\title{
Research of the size effect on shear strength of metal-plate connector joints in China
}

\author{
Chuang Wang ${ }^{1}$, Xinpei Zhang ${ }^{1, *}$, Peiyan Zhao ${ }^{1}$, and Zeli Que $^{2}$ \\ ${ }^{1}$ Sichuan University, School of Architecture and Environment, Wuhou District, Chengdu 610065, China \\ ${ }^{2}$ Nanjing Forestry University, College of Materials Science and Engineering, Nanjing 210037, China
}

\begin{abstract}
According to the reliability theory, the size effect has a great impact on the design value on shear strength of metal-plate connector. But little research has been done. So, based on GB/T50329-2002 of China, firstly, determining the size of metal-plate at different conditions, size effect tests were then conducted on metal-plate connectors composed of a type of Chinese metal-plate and 2\# SPF dimension lumber from North America. A total of 125 metal-plate connectors are tested at five angles $\left(90^{\circ}, 60^{\circ} \mathrm{T}, 120^{\circ} \mathrm{C}, 150^{\circ}\right.$ $\left.\mathrm{C}, 30^{\circ} \mathrm{T}\right)$, with Five kinds of widths $(50 \mathrm{~mm}, 85 \mathrm{~mm}, 125 \mathrm{~mm}, 150 \mathrm{~mm}, 180 \mathrm{~mm})$ for each angle. Based on the testing data, fitting curve of size effect is presented, and width-effect parameters are estimated with SPSS(Statistic Package for Social Science). Results indicate that the width effect is significant; shear strength increases with the increase of width, and stays stable after a certain width.
\end{abstract}

\section{INTRODUCTION}

Metal-plate connector (MPC) is a main form for lightframe wood residence [1-4]. In general, the design value of shear strength is an important parameter in designing MPC joints. But now, the design value of shear strength in GB50005-2003 [5] (Wood structure design standard in China) is determined by half probability-half empirical method which is referred to relative standard in Canada, failed to meet the requirements in GB500682001[6]( Unified standard for reliability of building structures in China).Besides, designing the shear tests of MPC joints by GB50005-2003 didn't specify the size of the plate, only ensuring that the length of plate should be as long as possible under the precondition of tooth failure. This method, which has to need many attempts to determine the Length-width ratio of the metal-plate, causes waste of time, materials; the error can't be estimated too. So, in order to specify the size of the plate and determine the design value of shear strength of MPC joints by the reliability theory, it' $s$ necessary to settle the problems of minimum Length-width ratio of the metal-plate and the width effect of it.

Now, the researches of MPC joints are concentrated on tension strength[7-11], bending strength[12-14]. But, it's limited on the width effect on shear strength[15-16] of MPC joints and minimum Length-width ratio of the metal-plate around the world. To settle these problems mentioned above, based on GB/T50329-2002[17] (Standard for methods testing of timber structures in China), a total of 125 MPC joints under 5 angles, each includes 5 different sizes of metal-plate were designed and tested on the shear strength.

\section{MATERIALS AND METHODS}

\subsection{Materials}

Dimension lumbers were obtained from Spruce-Pine-Fir \#2 grade(SPF II, equal to Grade III in China) dimensional lumber from North America, whose nominal crosssection size were $38 \mathrm{~mm} \times 89 \mathrm{~mm}, 38 \mathrm{~mm} \times 140 \mathrm{~mm}$, $38 \mathrm{~mm} \times 184 \mathrm{~mm}, 38 \mathrm{~mm} \times 235 \mathrm{~mm}, 38 \mathrm{~mm} \times 284 \mathrm{~mm}$ and moisture content was $10.4 \%-14.3 \%$.

Metal-plates were obtained from Wood structure of CROWNHOMES Technology Company Limited in Suzhou China and made by galvanizes steel. It was used Q235 steel with yield pressure strength of 276.24MPa, tensile yield strength of $352.68 \mathrm{MPa}$, elongation of 0.34 . The thickness of plate was about $1 \mathrm{~mm}$, the weight of galvanizing coat was $296 \mathrm{~g} / \mathrm{m} 2$, teeth density was per square centimeter of 1.20 and the teeth were $8.4 \mathrm{~mm}$ long and $3.2 \mathrm{~mm}$ wide (Fig. 1).

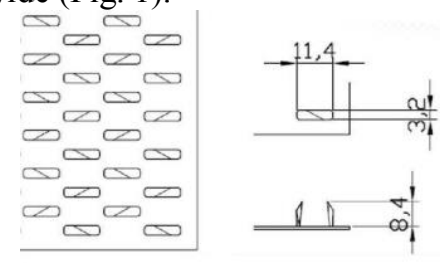

Fig. 1. Metal-plate.

\subsection{Size of MPC}

The shear tests of MPC had three failure forms, including Shear-Compression, Shear-Tension and Pure Shear. The design principle was the length of the metal-

* Xinpei Zhang: Xinpei5635@vip.sina.com 
plate should be as short as possible in the presence of these 3 failure forms. Through the pilot test of Lengthwidth ratio, around 2.7 was selected as Length-width ratio for Shear-Tension in $30^{\circ}$ and Shear-Compression in $150^{\circ}$; around 2.1 was selected as Length-width ratio for Pure Shear in $90^{\circ}$, Shear-Tension in $60^{\circ}$ and ShearCompression in $120^{\circ}$, which could meet the demands. According to the results of the pilot test of Length-width ratio and GB/T50329-2002, the shear tests of MPC joints were designed.

Table 1. Size of MPC joints.

\begin{tabular}{cccc}
\hline & \multicolumn{3}{c}{$\mathrm{A} / \mathrm{B} / \mathrm{C}$} \\
\hline & $\begin{array}{c}\text { Size of } \\
\text { plate }(\mathrm{mm})\end{array}$ & $\begin{array}{c}\text { Length- } \\
\text { width ratio }\end{array}$ & $\begin{array}{c}\text { Splicing form of } \\
\text { dimension lumber }\end{array}$ \\
\hline a & $180 \times 350$ & 1.94 & $\mathrm{f}$ \\
b & $150 \times 300$ & 2.00 & $\mathrm{~g}$ \\
c & $125 \times 250$ & 2.00 & $\mathrm{~h}$ \\
d & $85 \times 175$ & 2.05 & $\mathrm{i}$ \\
e & $50 \times 175$ & 3.50 & $\mathrm{i}$ \\
\hline & \multicolumn{3}{c}{$\mathrm{D} / \mathrm{E}$} \\
\hline & Size of & length- & Splicing form of \\
& plate $(\mathrm{mm})$ & width ratio & dimension lumber \\
\hline a & $180 \times 500$ & 2.78 & $\mathrm{f}$ \\
b & $150 \times 400$ & 2.67 & $\mathrm{~g}$ \\
c & $125 \times 350$ & 2.80 & $\mathrm{~h}$ \\
d & $85 \times 230$ & 2.70 & $\mathrm{i}$ \\
e & $50 \times 200$ & 4.00 & $\mathrm{j}$
\end{tabular}

Width of plate ranged from $50 \mathrm{~mm}, 85 \mathrm{~mm}, 125 \mathrm{~mm}$, $150 \mathrm{~mm}$ to $180 \mathrm{~mm}$ that were common used in engineering. The pure shear in $90^{\circ}$ was named A group, shear-tension in $60^{\circ}$ named B group, shear-compression in $120^{\circ}$ named $\mathrm{C}$ group, shear-tension in $30^{\circ}$ named $\mathrm{D}$ group, shear-compression in $150^{\circ}$ named E group. Each group used 5 different width of plate mentioned above, then the width were numbered a, b, c, d, e in descending order. This test, the available sizes of dimension lumber were insufficient when placing $180 \mathrm{~mm}$ wide and $150 \mathrm{~mm}$ wide metal-plate. Therefore, two the same size dimension lumbers were used to make the splice. The splicing form of each dimension lumber with a section size of $38 \mathrm{~mm} \times 235 \mathrm{~mm}$ putting on left and right, two the same dimension lumber with a section size of $38 \mathrm{~mm} \times 235 \mathrm{~mm}$ in the middle was called $\mathrm{f}$; the splicing form of each dimension lumber with a section size of $38 \mathrm{~mm} \times 184 \mathrm{~mm}$ putting on left and right, two the same dimension lumber with a section size of $38 \mathrm{~mm} \times 184 \mathrm{~mm}$ in the middle called was g; the splicing form of each dimension lumber with a section size of $38 \mathrm{~mm} \times 184 \mathrm{~mm}$ putting on left and right, one dimension lumber with a section size of $38 \mathrm{~mm} \times 286 \mathrm{~mm}$ in the middle was called $\mathrm{h}$; the splicing form of each dimension lumber with a section size of $38 \mathrm{~mm} \times 140 \mathrm{~mm}$ putting on left and right, one dimension lumber with a section size of $38 \mathrm{~mm} \times 235 \mathrm{~mm}$ in the middle was called $\mathrm{i}$; the splicing form of each dimension lumber with a section size of $38 \mathrm{~mm} \times 140 \mathrm{~mm}$ putting on left and right, one dimension lumber with a section size of $38 \mathrm{~mm} \times 184 \mathrm{~mm}$ in the middle was called j. Size of metal-plate, Length-width ratio, splicing form of dimension lumbers were shown in Table 1. Based on GB/T50329-2002, parting all MPC joints into 25 groups (5 angles $\times 5$ widths) by $\mathrm{Aa} \sim \mathrm{Ae}$, $\mathrm{Ba} \sim \mathrm{Be}, \mathrm{Ca} \sim \mathrm{Ce}, \mathrm{Da} \sim \mathrm{De}, \mathrm{Ea} \sim \mathrm{Ee}$, each group including 5 MPC joints.

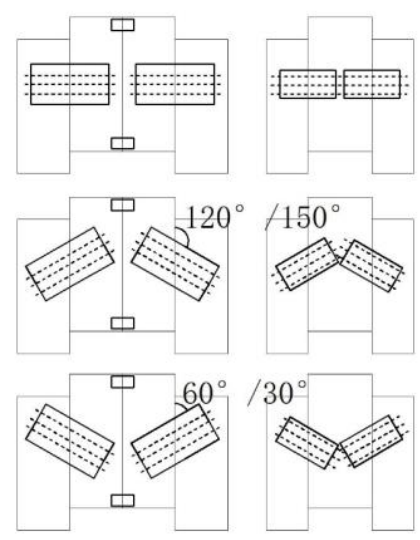

Fig. 2. Sketch map of MPC.

\subsection{Methods}

It is known that the properties of plate will differ if the teeth widths parallel or perpendicular to the plate widths and plate lengths. In this paper, just one orientation was investigated, teeth widths parallel to plate widths.

Adopt 200T universal testing machine YAW - 2000 and the corresponding analysis system, relative position of metal-plate and dimension lumbers were shown in Figure 2.Based on GB50329-2002, uniform speed was needed, and reached ultimate shear strength within 5 - 20 min. So, this test, selecting equal-displacement loading by $1.0 \pm 0.5 \mathrm{~mm} / \mathrm{min}$ and different groups were used corresponding loading speed under this standard mentioned above. Recording the failure form after the test, taking maximum load in the $\mathrm{p}-\Delta$ curve as test results of shear strength of MPC joints. But, if relative slip of adjoining dimension lumbers over the larger value of $6 \mathrm{~mm}$ or 6 times of plate thickness, the shear strength will be the load instead related to the larger value. So, considering the strength correction coefficient, then dividing the total length $(\mathrm{mm})$ of shear plane of plate which was paralleled to load direction of metal-plate connector, the shear strength of metal-plate connector (MPa) can be got.

\section{RESULTS AND DISCUSSION}

\subsection{Minimum length-width ratio}

All MPC in each group appeared expected failure form, based on the tests results, Fig. 3 was drew with the width $(\mathrm{mm})$ of plate as the horizontal axis, the Lengthwidth ratio as the vertical axis. In the Fig. 3, the black solid line represents the connection of each minimum Length-width ratio, and the black dotted line is the final value line. From Fig. 3, when the width of plate is short, the Length-width ratio is larger; as the width increasing, the Length-width ratio is decreasing. After $85 \mathrm{~mm}$, the change is not obvious any more. when the width of plate is equal or greater than $85 \mathrm{~mm}$, conventionally, the Length-width ratio takes to $2.05\left(90^{\circ}, 60^{\circ} \mathrm{T}\right.$ and $\left.120^{\circ} \mathrm{C}\right)$ or $2.7\left(30^{\circ} \mathrm{T}\right.$ and $\left.150^{\circ} \mathrm{C}\right)$ can meet the requirements. 
For the big size plate, if the Length-width ratio is smaller than the 2 numbers above, the failure form for prediction
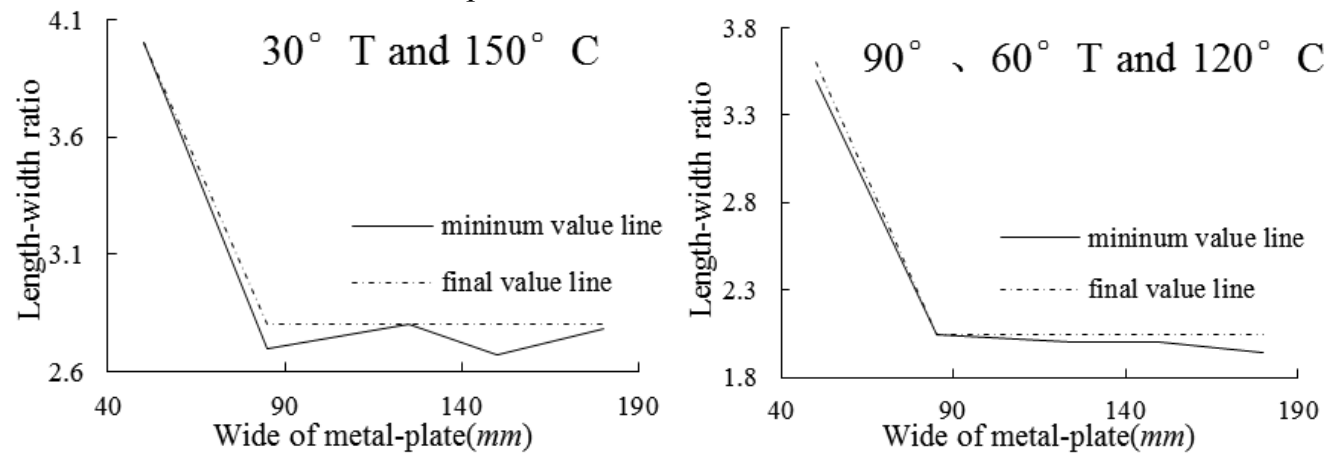

Fig. 3. Relationship between Length-width ratio and width of metal-plate.

Table 2. Value of Length-width ratio.

\begin{tabular}{ccc}
\hline Width of plate $(\mathrm{mm})$ & $150^{\circ} \mathrm{C}, 30^{\circ} \mathrm{T}$ & $90^{\circ}, 60^{\circ} \mathrm{T}, 120^{\circ} \mathrm{C}$ \\
\hline 50 & 4.00 & 3.60 \\
$85,125,150,180$ & 2.80 & 2.05 \\
\hline
\end{tabular}

Table 3. Shear strength and B value of Shear strength.

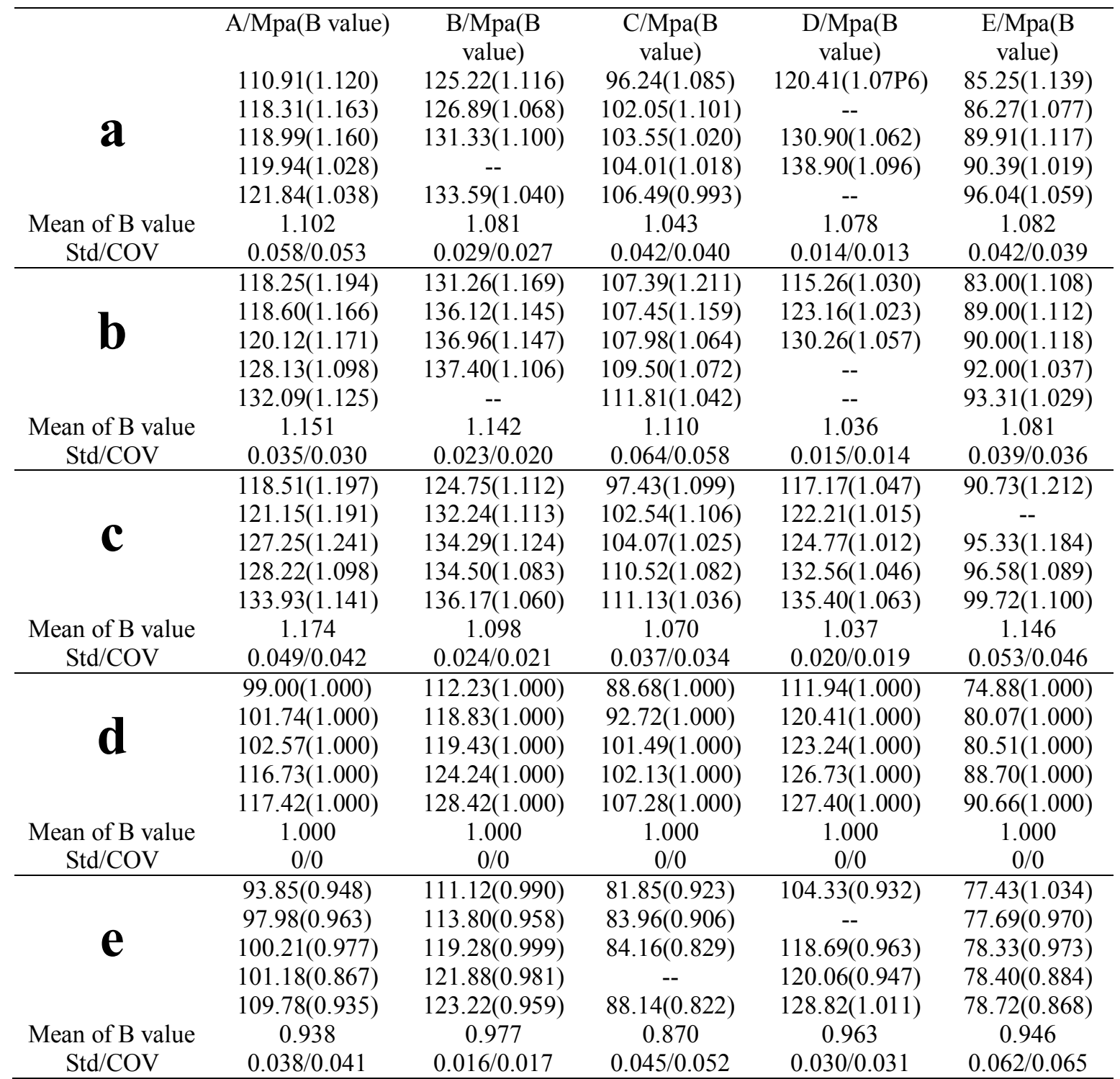

Note: the missing data are existing but can't be used for processing errors in specimen or occurring abnormal phenomena during experiment. 
Table 4. Variance of analysis on Shear strength of metal-plate joints.

\begin{tabular}{ccccccc}
\hline Performance index & Sources of variation & Sum of squares & Df & Mean square & F & Sig \\
\hline \multirow{3}{*}{ Shear strength } & among groups & 2305.782 & 4 & 576.445 & 13.951 & 0.000 \\
& within groups & 826.410 & 20 & 41.320 & & \\
& summation & 3131.191 & 24 & & & \\
\hline
\end{tabular}

The value of minimum Length-width ratio just needs to be equal with the black solid line or greater than it. For practical use, a descending line was taken before $85 \mathrm{~mm}$ and horizontal line after $85 \mathrm{~mm}$.So, for $50 \mathrm{~mm}$ width plate, the minimum Length-width ratio takes 4 in $150^{\circ} \mathrm{C}, 30^{\circ} \mathrm{T}$, and 3.6 in $90^{\circ}, 60^{\circ} \mathrm{T}, 120^{\circ} \mathrm{C}$; for other wide plate in this tests, the minimum Length-width ratio takes 2.8 in $150^{\circ} \mathrm{C}, 30^{\circ} \mathrm{T}$, and 2.05 in $90^{\circ}, 60^{\circ} \mathrm{T}, 120^{\circ} \mathrm{C}$ as shown in Table 2. This article suggests that the main function of length of the plate is fixed the position of plate and transfers the force uniformly, if the failure form can be ensured to appear, and the effect of length of the plate can be ignored. So, it's safe and suitable to use the minimum Length-width ratio in Fig. 3 to design the size of plate in engineering.

\subsection{Size effects of width}

Sort the shear strength from small to large for each group and the ratio of the shear strength of each group to the corresponding strength of $85 \mathrm{~mm}$ width plate is defined as B.

The results are shown in Table 3 which followed the above method, and the mean value curve of $\mathrm{B}$ for all groups are shown in Fig. 4, and one-way ANOVA is shown in Table $4\left(90^{\circ}\right.$, other angles are comparable). From Table 3, variable coefficients of the shear strength are between $1.3 \%-6.5 \%$ which have minor differences, indicating that different sizes of metal-plate connectors have high similarity, also showing that the subsequent analysis is scientific.

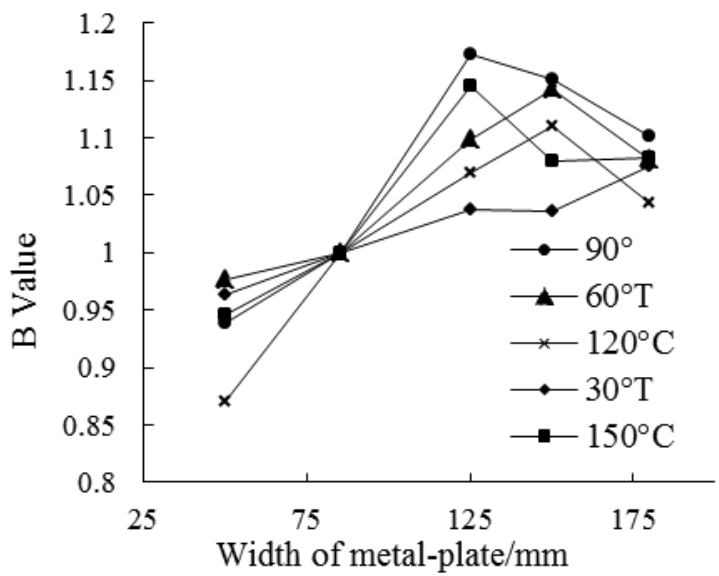

Fig. 4. Relationship between Width of metal-plate and B value of Shear strength.

From Table 3 and Fig. 4 we can see, the size effect is obvious on the shear strength in $60^{\circ} \mathrm{T}$ and $120^{\circ} \mathrm{C}$; from $50 \mathrm{~mm}$ to $150 \mathrm{~mm}$ of the plate width, the shear strength increases obviously; and for $120^{\circ} \mathrm{C}$, the mean of shear strength from $50 \mathrm{~mm}$ to $85 \mathrm{~mm}$ increases by a large amount by $14.94 \%$, has declines slightly when $180 \mathrm{~mm}$; the size effect is relatively obvious of the shear strength in $30^{\circ} \mathrm{T}$, the mean of shear strength from $50 \mathrm{~mm}$ to $85 \mathrm{~mm}$ slowly increases by $3.84 \%$, almost unchanged from $125 \mathrm{~mm}$ to $150 \mathrm{~mm}$; the size effect is less obvious of the shear strength in $90^{\circ}$ and $150^{\circ} \mathrm{C}$, from $50 \mathrm{~mm}$ to $125 \mathrm{~mm}$ of the plate width, the shear strength increases obviously; and for $90^{\circ}$, the mean of shear strength from $50 \mathrm{~mm}$ to $125 \mathrm{~mm}$ increases by $6.61 \%$, has declined slightly from $125 \mathrm{~mm}$ to $180 \mathrm{~mm}$, and for $150^{\circ} \mathrm{C}$, the same situation like $90^{\circ}$ from $50 \mathrm{~mm}$ to $150 \mathrm{~mm}$, and from $150 \mathrm{~mm}$ to $180 \mathrm{~mm}$, the shear strength almost stay unchanged.

Compared with small size plate, the shear strength didn't increase, but lower of all of $180 \mathrm{~mm}$ width plates and a part of $150 \mathrm{~mm}$ width plates. The reason is the limitation of the loading device, causing eccentricity and torsional in large size plate, such as $180 \mathrm{~mm}$ width plate, and not fully utilizing proper performance when damaged. So the test results of shear strength were smaller, when considering the shear strength of $180 \mathrm{~mm}$ width plate, as the same to $150 \mathrm{~mm}$.

The change of strength is related to many factors, and the function of variance analysis is to obtain the relationship among various factors through the analysis of experimental data, then determine the factors which remarkable influenced the shear strength and the degree of impact. From one-way ANOVA shown in table 4,the derivate square between groups by 2305.782 is greater than within groups by 826.410 , which means the effect of width on shear strength is far greater than that of random error; $\mathrm{F}=13.951$ is far more than 1 , which suggests that the difference of shear strength could be of great significance for each width, when significant level is $0.05, \mathrm{P}<0.01$ for shear strength, which suggests that under the situation of this test, width of plate has a deep impact on shear strength.

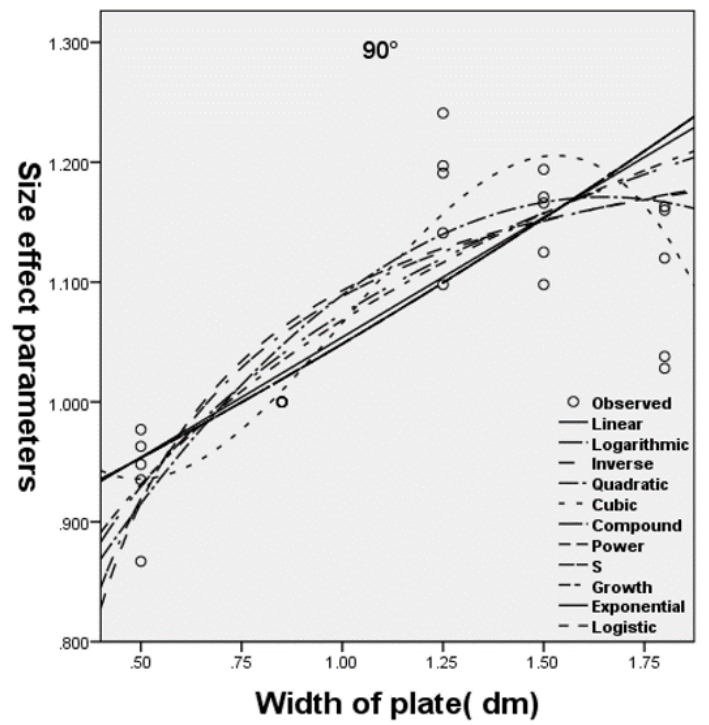

Fig. 5. Relationship between width of metal-plate and size effect parameters. 
Table 5. Variance of analysis on Shear strength of metal-plate joints.

\begin{tabular}{ccccccccc}
\hline Angle & \multicolumn{3}{c}{ Estimation of parameters } & \multicolumn{4}{c}{ Width(dm) } \\
\cline { 2 - 8 } & $\mathbf{b}_{\mathbf{0}}$ & $\mathbf{b}_{\mathbf{1}}$ & $\mathbf{b}_{\mathbf{2}}$ & $\mathbf{b}_{\mathbf{3}}$ & 0.5 & 0.85 & 1.25 & $\geq 1.5$ \\
\hline $90^{\circ}$ & 1.106 & -0.863 & 1.257 & -0.434 & 0.92 & 1.01 & 1.14 & 1.17 \\
$60^{\circ} \mathrm{T}$ & 1.299 & -1.244 & 1.426 & -0.446 & 0.98 & 1.00 & 1.10 & 1.14 \\
$120^{\circ} \mathrm{C}$ & 0.701 & 0.290 & 0.169 & -0.124 & 0.87 & 1.00 & 1.09 & 1.10 \\
$30^{\circ} \mathrm{T}$ & 0.840 & 0.346 & -0.238 & 0.065 & 0.96 & 1.00 & 1.03 & 1.04 \\
$150^{\circ} \mathrm{C}$ & 0.906 & -0.089 & 0.404 & -0.168 & 0.94 & 1.02 & 1.10 & 1.11 \\
\hline
\end{tabular}

\subsection{Size effects curve fitting}

The width $(\mathrm{dm})$ of plate to be seen as independent variables, B value to be seen as dependent variables, then, on the basis of least squares theory, size effect curve fitting with SPSS was set up. The fitting curves were including logistic, linear, inverse, exponential and so on. Taking $90^{\circ}$ for example (other angles are comparable), as shown in Fig. 5. According to the analysis, cubic curve was the best fitted one. The Goodness of Fit: R2 was between $76 \%$ and $90 \%$ among $90^{\circ}, 30^{\circ} \mathrm{T}, 60^{\circ} \mathrm{T}$, and $60 \%$ for $150^{\circ} \mathrm{C}$, Sig value was below 0.001. Fitted curve as Eq.1, estimation of parameters with SPSS for all groups as Table 5, then, the size effect coefficients could be got through Eq.1, and multiplied shear strength of $85 \mathrm{~mm}$ width plate for relative angles, so, the shear strength was got at any angle or any width of metal-plate connector.

$$
y=\mathbf{b}_{0}+\mathbf{b}_{1} x+\mathbf{b}_{2} x^{2}+\mathbf{b}_{3} x^{3}
$$

\section{Conclusions}

The main points developed from above could be summarized as follow:

For widely used $50 \mathrm{~mm}$ wide plate, the minimum Length-width ratio taking 4.00 in $150^{\circ} \mathrm{C}, 30^{\circ} \mathrm{T}$, and 3.60 in $90^{\circ}, 60^{\circ} \mathrm{T}, 120^{\circ} \mathrm{C}$ can ensure the normal failure form to appear. For widely used $85 \mathrm{~mm}, 125 \mathrm{~mm}, 150 \mathrm{~mm}$, $180 \mathrm{~mm}$ wide plate, the minimum Length-width ratio taking 2.80 in $150^{\circ} \mathrm{C}, 30^{\circ} \mathrm{T}$, and 2.05 in $90^{\circ}, 60^{\circ} \mathrm{T}$, $120^{\circ} \mathrm{C}$ can ensure the normal failure form to appear.

Size effects of width on shear strength is obvious, the shear strength was larger as the width of the plate increasing from $50 \mathrm{~mm}$ to $125 \mathrm{~mm}$, and been stable from $125 \mathrm{~mm}$ to $180 \mathrm{~mm}$.

The cubic curve fitting with width and B value saw Eq.1. For plate at any angle or any width, taking the shear strength of $85 \mathrm{~mm}$ wide plate as the benchmark in this paper, we can figure B value out by Eq.1, and multiply shear strength of $85 \mathrm{~mm}$ wide plate for relative angles. The shear strength is got for any angle or any width of metal-plate connector.

The conclusions above not only settled the size of plate when design shear tests (minimum Length-width ratio of plate), but also figured out size effects of width which could serve as a theoretical basis for determining design value of shear strength of metal-plate connector through the reliability theory in China.

The research work was supported by National Key R\&D Program of China under Grant "2017YFC0703501".

\section{References}

1. Takashiro, S., Inoue, T, Resarch report of Japanese architecture society, 3,117-120 (2013)

2. He, M., Lam, F, Struct. Eng.,1,1-5 (2004)

3. Cramer, S. M., Drozdek, J. M., Wolfe, R. W, J. Struct. Eng., 126(12), 1388-1394(2000)

4. Fei, B. H., Wang, G., Ren, H. Q., Yan, Y. U, Chin. Wood Ind.,5,6-9(2002).

5. China Standards Publication, Code for design of timber structures: GB50005-2003 (China Architecture \& Building Press, Beijing, 2003).

6. China Standards Publication, Unified standard for reliability of building structures : GB50068-2001 (China Architecture \& Building Press, Beijing, 2001).

7. Guo, W., Song, S., Jiang, Z., Wang, G., Sun, Z., Wanng, X., et al, J. Mater. Sci. Res., 3(3), 40-47 (2014).

8. Guo, W., Song, S., Zhao, R., Ren, H., Jiang, Z., Wang, G., et al, Bioresources, 8(4), 5666-5677 (2013).

9. Gupta, R, J. Soc. Wood Sci. Technol., 26(2), 212222 (1994).

10. Gebremedhin, K. G., Jorgensen, M. C., Woelfel, C. B, Wood Fiber Sci., 24(2), 118-132 (1992).

11. Gebremedhin, K. G., Crovella, P. L, Trans. ASAE, 34(1), 0281(1991).

12. Güntekin, E, Turk. J. Agric. For., 31(3), 207212(2007).

13. P. J. O' Regan, Woeste, F. E., Chairman, J. R., Loferski, A. G., Zink, J. V., Perumpral, Vi. Tech (1997),pp. 23-38.

14. Wolfe, R. W, For. Prod. J., 40(9), 17-23 (1990).

15. Wang, Experimental Investigation on Shear Behavior of Mental-Plate-Connected Joints (Unpublished MA.Eng. dissertation, Chongqing University, 2011) .

16. Clouston, P. L., Schreyer, A. C, Structures Congress 2011, pp. 626-635.

17. China Standards Publication, Standard for methods testing of timber structures : GB/T50329-2002 (China Architecture \& Building Press, Beijing, 2002).

\footnotetext{
Xinpei Zhang: Xinpei5635@vip.sina.com
} 